\title{
AS CONTRIBUIÇÕES DA UNIVERSIDADE ABERTA PARAA TERCEIRA IDADE NO ENVELHECIMENTO SAUDÁVEL
}

\author{
Francieli Webber* \\ Kátia Lilian Sedrez Celich**
}

\section{Resumo}

Trata-se de um estudo qualitativo de abordagem exploratória e descritiva, realizado com 10 idosos que participam do programa "Universidade Sem Limites", da Universidade Regional Integrada - Campus de Erechim/RS. O presente estudo buscou identificar as contribuições da participação do idoso nesse programa para sua vida. A coleta das informações ocorreu através de uma entrevista semi-estruturada contendo uma questão norteadora: Quais foram as contribuições que ocorreram em sua vida a partir de sua participação na Universidade Sem Limites? A análise permitiu organizar as informações em quatro áreas principais: Contribuições na vida pessoal: melhora da auto-estima, auto-imagem e cognição. Contribuições na vida familiar: favorecimento das relações intergeracionais. Contribuições nos relacionamentos com amigos/sociedade: veículo de estímulo ao convívio social, autonomia, independência e responsabilidade com a vida e com o outro. Contribuições no exercício de sua cidadania: promovendo a capacidade de exigência dos seus direitos e a autonomia de pensamento, como membros úteis da sociedade, atuando com base em princípios sociais e humanísticos. A participação do idoso nesse programa contribui de maneira singular em vários aspectos de sua vida. Portanto, este espaço surge como uma possibilidade de um envelhecer mais saudável, onde o idoso tem a oportunidade de interagir com outros idosos e desenvolver aspectos físicos, cognitivos, sociais, emocionais e espirituais, sendo o próprio idoso o agente do processo educativo, o que contribui para a elevação dos níveis de vida e saúde e valoriza as competências sócioemocionais adquiridas pelos idosos ao longo da vida.

Palavras-chave: Envelhecimento. Qualidade de vida. Educação.

* Acadêmica do nono semestre do Curso de Enfermagem da Universidade Regional Integrada do Alto Uruguai e das Missões — Campus de Erechim — RS. E-mail: francieli_webber@yahoo.com.br

** Doutoranda em Gerontologia Biomédica pela Pontifícia Universidade Católica do Rio Grande do Sul (PUCRS). Mestre em Enfermagem pela Escola de Enfermagem da Universidade Federal do Rio Grande do Sul. Professora do Curso de Graduação em Enfermagem da Universidade Regional Integrada do Alto Uruguai e das Missões — Campus de Erechim _ RS. E-mail: celich@clicalpha.com.br

Estud. interdiscip. envelhec., Porto Alegre, v. 12, p. 127-142, 2007. 


\section{Introdução}

Tendo em vista o crescente aumento da população idosa no Brasil, nas últimas décadas, o envelhecimento tornou-se um fenômeno bastante comum, fato caracterizado pela observação de um número maior de idosos em filas de banco, freqüentando praças, clubes e outras atividades sociais e culturais, bem como os dados apresentados pelo Instituto Brasileiro de Geografia e Estatística (INSTITUTO BRASILEIRO DE GEOGRAFIA E ESTATÍSTICA, 2000).

$\mathrm{O}$ envelhecimento é um fenômeno universal e inerente a todo o indivíduo, constituindo-se em um processo de alterações morfológicas e funcionais do organismo à medida que o tempo passa. É um fato inevitável que se apresenta no cotidiano do ser humano, varia não só de um órgão a outro, bem como entre pessoas de mesma idade. É um aspecto da vida diária que se expressa com mais vigor a cada dia e a cada instante (JECKEL NETO, 2002; NETTO; PONTE, 2005).

Envelhecer é um processo tão natural e esperado quanto nascer, crescer e mudar; mudar no sentido de sofrer transformações acompanhadas de alterações, que vão desde a aparência física ao comportamento e aos papéis sociais, passando pelas experiências e relações estabelecidas ao longo dos anos (PORTELLA, 2004).

O envelhecimento humano, assim como as demais etapas da vida, é um processo de transformação do organismo que se reflete nas suas estruturas físicas, nas manifestações cognitivas, bem como na percepção subjetiva dessas transformações (PARENTE, 2006). É importante considerar que não existe um só envelhecer, mas processos de envelhecimento — de gênero, etnia, de classe social, de cultura - determinados socialmente. As desigualdades do processo de envelhecimento se devem, basicamente, às condições desiguais de vida e de trabalho a que estiveram submetidas as pessoas idosas (BOUTIQUE; SANTOS, 2005).

Portanto, o processo de envelhecimento é multifatorial, tem seu componente genético, que parece influenciar 30\% de todo o processo, e que é fortemente modulado pelo ambiente e ainda pelos componentes sociais, culturais e psicológicos. Assim, o estilo de vida é um dos mais importantes determinantes da saúde de indivíduos, grupos e comunidades (BERLIZI; ROSA, 2002). 
Diante deste contexto, o estilo de vida ativo passou a ser considerado fundamental na promoção da saúde e redução da mortalidade, sendo que o comportamento assumido pelo indivíduo torna-se um fator decisivo na conquista do envelhecimento saudável (BERLIZI; ROSA, 2002).

$\mathrm{O}$ ritmo acelerado do processo de envelhecimento cria novos desafios, no contexto atual, para a sociedade, que, por sua vez, convive diariamente com profundas transformações sociais, dentre as quais vale destacar o ingresso do idoso nas universidades abertas para a terceira idade ${ }^{1}$. Há uma nova concepção de velhice na atualidade, deixando esta de ser sinônimo de doença, solidão e dependência (MORAES, 2004). Muitas pessoas chegam à terceira idade saudáveis ou apresentando boa capacidade funcional, intelectual e cognitiva.

Entretanto, diante da aposentadoria, quando passam a ter um tempo maior, em alguns casos, este fato pode ser uma porta de entrada para o início de uma crise, pois se vêem despreparados diante dessa novidade (SOUZA, 2001). Para Moragas (1997, p. 218): “O tempo é ambivalente: pode ser benéfico ou prejudicial, de acordo com as condições da pessoa e do meio, se o tempo livre não for preenchido com atividades significativas para a pessoa, pode se tornar uma carga". Assim, vê-se que este espaço precisa ser ocupado com algo que dê sentido à vida do idoso.

A partir dos anos 80, mas de maneira mais acentuada na década de 90, observa-se uma ocorrência maior de interesse pelo destino dos idosos no país, refletindo no aumento da consciência sobre os efeitos do envelhecimento populacional concernentes às questões econômicas, sociais e de saúde. Nessa perspectiva, alguns segmentos da sociedade vêm buscando promover programas que dêem conta dos desafios que essa nova visão de velhice está trazendo.

Nesse contexto, é notável o grande número de universidades abertas para a terceira idade que surgiram vinculadas, na grande maioria, a instituições de ensino superior (SOUZA, 2001). As universidades para a terceira idade constituem-se em espaços para aquisição de conhecimentos, melhoria da auto-estima e ampliação da rede de sociabilidade dos idosos (GOLDMAN, 2006).

\footnotetext{
${ }^{1}$ Universidade Aberta para a Terceira Idade, neste estudo, é entendida como Universidade Sem Limites, pois na instituição, campo de pesquisa, é assim que esse programa é conhecido e denominado. Segundo Veras e Caldas (2004) as Universidades da Terceira Idade representam uma nova forma de promover a saúde da pessoa que envelhece, a partir de uma ação interdisciplinar comprometida com a inserção do idoso como cidadão ativo na sociedade. Palma (2000) chama a atenção para criação destes programas com o objetivo de tirar os idosos do isolamento.
}

Estud. interdiscip. envelhec., Porto Alegre, v. 12, p. 127-142, 2007. 
Os programas das Universidades da Terceira idade, na grande maioria se caracterizam como espaços propostos à educação permanente, que é concebida como um contexto educativo global, sem limites de idade, que surge da necessidade de se acompanharem as rápidas transformações que estão acontecendo no mundo, relacionadas aos aspectos econômico, político, social e cultural (IRIGARAY, 2006). O ingresso do idoso na Universidade vem contemplar uma forte e crescente demanda por educação que existia nos segmentos populacionais, que envelhecem à margem da educação, e que vêem nesta a oportunidade de aquisição de conhecimentos, bem como a ascensão social.

O programa da "Universidade Sem Limites" da Universidade Regional Integrada do Alto Uruguai e das Missões (URI) - Campus de Erechim, iniciou suas atividades no ano de 1991 e hoje atende aproximadamente 70 idosas, sendo que nem todas freqüentam os encontros com regularidade. Normalmente, 30 senhoras participam todas as semanas.

O Programa de Integração da Universidade com a terceira idade, do Departamento de Ciências Humanas da URI — Campus de Erechim, vem desenvolvendo projetos que visem à integração e à participação efetiva do grupo de idosas no meio acadêmico, bem como no contexto social, e tem como objetivos:

a) ampliar conceitos e informações sobre o envelhecimento; interação sócio-afetiva;

b) congregar pessoas para discussão de temas sobre qualidade de vida e envelhecimento;

c) oportunizar a qualidade de vida e convivência grupal;

d) promover uma velhice saudável;

e) socializar experiências;

f) sistematizar as vivências em forma de produção. (UNIVERSIDADE REGIONAL INTEGRADA DO ALTO URUGUAI E DAS MISSÕES, 2006).

Esse espaço surge como uma possibilidade de um envelhecer mais saudável, onde o idoso tem a oportunidade de interagir com outros idosos e desenvolver aspectos físicos, cognitivos, sociais, emocionais e espirituais. Por isso, o trabalho é feito "com o idoso" e não "para o idoso", por entender-se que este é o agente do processo educativo (SOUZA, 2001). Acredita-se que a participação do idoso nestes espaços possa auxiliar na ressignificação de sua velhice. 
Aranda e Horna (2007), ao realizarem um estudo que avaliava a satisfação de idosas pela vida, evidenciaram que aquelas que tinham suporte social e conviviam com seus familiares e amigos eram mais felizes. Outro fato demonstrado pela pesquisa é que as idosas mais comunicativas e expressivas relatam sentimentos de alegria e satisfação com a vida. Tirar os idosos do isolamento social, propiciar-lhes saúde e interesse pela vida e modificar sua imagem perante a sociedade foram, desde o início, um dos objetivos da Universidade da Terceira Idade (CACHIONI; NERI, 2004).

Diante dessas assertivas, o processo educativo consiste em projetar, no indivíduo, a possibilidade de apropriar-se de sua própria experiência e de partilhar com as experiências dos outros - o que, para o idoso, significa melhoria das condições de saúde, independência e capacidade de autocuidado (MARIN et al, 2003). A educação baseia-se no encorajamento e apoio para que as pessoas e grupos sociais assumam maior controle sobre sua saúde e suas vidas (VASCONCELOS, 2001).

Diante dessas considerações, este estudo tem como objetivo: identificar as contribuições que a participação do idoso no programa Universidade Sem Limites apresenta para sua vida.

\section{Metodologia}

Trata-se de um estudo qualitativo de abordagem exploratória e descritiva. O local escolhido para a realização da pesquisa, foi a Universidade Regional Integrada do Alto Uruguai e das Missões - Campus de Erechim (RS), no programa de Integração da Universidade com a terceira idade, do Departamento de Ciências Humanas. A população do estudo foi composta de dez idosas que participam do referido programa. Todas as participantes são do sexo feminino porque, nessa instituição, esse programa é oferecido somente para mulheres. O projeto da pesquisa foi aprovado pelo Comitê de Ética em Pesquisa da referida Universidade, Resolução ${ }^{\circ}$. 079/TCH/06. Todos os participantes assinaram o Termo de Consentimento Livre e Esclarecido, onde deram seu consentimento para divulgação dos resultados, sendo garantido seu anonimato. A coleta de dados foi realizada no período de janeiro a março de 2007. Como instrumento metodológico, utilizou-se uma entrevista com uma questão norteadora: Que contribuições trouxe para sua vida sua participação na Universidade Sem Limites? As entrevistas foram gravadas e transcritas na íntegra para após serem 
analisadas, conforme propõe Minayo (2000). As fitas foram inutilizadas e as transcrições ficarão de posse das pesquisadoras e serão guardadas por cinco anos, sendo depois destruídas. O respeito aos indivíduos foi mantido; portanto, para identificação utilizou-se, na análise, P que significa participante e números arábicos em ordem cronológica conforme ocorreram às entrevistas.

\section{Contribuições da Universidade sem Limites no Envelhecimento Saudável}

Neste momento do estudo, apresentam-se os temas que emergiram da análise das entrevistas, os quais descrevem as contribuições provenientes da participação dos idosos na Universidade sem Limites, em seu envelhecimento saudável.

\subsection{Em Relação à Vida Pessoal}

Nesta área temática, foi possível observar que a participação dos idosos nesse programa melhorou sua auto-estima, a auto-imagem e alguns aspectos cognitivos. Ainda, permitiu vencer alguns obstáculos como a timidez. Fato evidenciado no fragmento das seguintes falas:

Eu fiquei mais solta, mais feliz, porque agora tenho para onde ir, não fico só em casa, porque em casa dá depressão, e participar é também um lazer e se faz novas amizades, se troca idéias, um ajuda o outro [. . . ]. (P1).

Eu cresci mais, a minha auto-estima se elevou, eu me sinto mais segura com relação à convivência na sociedade, até me sinto importante, agora participo na comunidade sem medo. (P2).

Depois que eu entrei na URI, no curso para idosas, foi maravilhoso, gosto muito. Me sinto bem fisicamente e mentalmente, em todos os sentidos, me sinto mais capacitada a participar das atividades, me sinto mais à vontade para apresentar trabalhos perante as outras pessoas, antes eu não tinha essa liberdade, essa coragem [. . .]. (P9). 
[...] me sinto mais jovem, mais esperta, vi que sou inteligente, eu me valorizo, tenho mais ânimo para viver, me sinto jovem por dentro [. . . ] eu tava meio esquecida, mas até isso me fez limpar a memória. (P10).

De acordo com os discursos, é possível observar que o entendimento das participantes em relação à vida pessoal está interligado à vida em sociedade. Esse fato pode ser compreendido, na medida em que se pensa e se percebe o ser humano em sua totalidade existencial, sendo este um ser de relação que se desenvolve na presença do outro (CELICH, 2004). Poder sair de casa, ter um local onde podem se divertir, aprender e interagir com outras pessoas tem um significado relevante no cotidiano dessas idosas. $\mathrm{O}$ contato das idosas com a universidade lhes proporciona um motivo para sair regularmente de casa, uma oportunidade de contato social; a ausência deste contato torna-se um problema extremamente negativo para a saúde tanto mental, quanto física. Esse entendimento é verbalizado por algumas idosas (PORTELLA, 2004).

Salientam-se também as evidentes mudanças benéficas em suas vidas pessoais, como crescimento intelectual, elevação da auto-estima, valorização de suas próprias bagagens culturais e a descoberta de novos potenciais, o que contribui para uma nova visão de envelhecimento. Segundo Neri (2005), a participação na universidade aberta para a terceira idade intensifica os contatos sociais, a troca de vivências e os conhecimentos, promove o aperfeiçoamento pessoal e a flexibilidade intelectual de adultos maduros e idosos.

Os depoimentos ainda desvelaram que a participação das idosas na Universidade Sem Limites faculta-lhes a possibilidade de conhecer outras pessoas, redescobrir-se, trocar e partilhar vivências e sonhos, estabelecer ajuda mútua, vislumbrar novos horizontes, vencer algumas barreiras do passado, assim como aguçar a sua independência física, mental e social, desenvolver a criatividade, facilitar a socialização com pessoas estranhas, aprender a lidar com perdas que vêm junto com o envelhecimento, usufruir do prazer encontrado nas pequenas coisas, promovendo assim uma velhice prazerosa. Souza (2001) ressalta que a universidade aberta para a terceira idade abre novos horizontes ao idoso, dando-lhe condições para experimentar maior liberdade interior e exterior e sentir e expressar a sua personalidade de forma mais autônoma e autêntica. Tal sentimento foi evidenciado nos relatos destas idosas. 


\subsection{Em sua Vida Familiar}

Neste tema emerge o favorecimento das relações intergeracionais. A família aparece como sendo um local onde é possível se conviver de maneira mais harmônica, quando se é capaz de entender e respeitar as outras gerações. Esses sentimentos são descritos pelas participantes da seguinte maneira:

Aprendi a valorizar mais as pessoas, os empregados, o marido, os filhos [...] agente se sente mais gente, mais feliz [...]. (P1).

[...] a gente aprende até como conviver com a família, eles dão um sentido, como tratar, hoje eu vivo muito bem com a minha família, como amiga, esposa, mãe e avó. Trocamos muitas idéias, qualquer coisa um já comunica e ajuda o outro. (P5).

Aprendi muitas coisas novas na URI, penso menos nas doenças, fiquei mais agradável com a minha família, os meus filhos se sentem bem quando estão comigo, eles gostam muito que eu participe, sabem que lá não estou sozinha, hoje não fico dependendo só deles, faço o que gosto. (P8).

Melhorou muito com minha família depois que eu comecei a participar do grupo, o que eu aprendo nas palestras da URI levo para eles, nosso convívio melhorou [...]. (P9).

Hoje, consigo valorizar mais a minha família, aprendi muita coisa para mim e para eles. Eles se sentem bem com uma pessoa assim em casa [. . .] sou uma velha alegre. Quando eu retorno para casa eu levo felicidade, a minha família me vê feliz e se sente feliz, também. (P10).

Os depoimentos acima demonstram algumas mudanças nas atitudes e comportamento das idosas, a partir do convívio em um ambiente agradável, que lhes proporciona prazer e amplia alguns conceitos de modo 
a interferir, positivamente, no contexto familiar. Estudo realizado por Portella, na região do Alto Uruguai, identificou que a participação dos idosos nos grupos de terceira idade, traz benefícios aos idosos, sendo extensivo aos seus familiares, uma vez que eles gastam suas energias, trocam experiências, se distraem, têm esse novo compromisso a se dedicar e acabam esquecendo das doenças (PORTELLA, 2001). Conseqüentemente, queixamse e adoecem menos, deixando assim de sobrecarregar seus familiares. Ainda, emerge das falas a valorização da família como uma sensibilidade que foi aguçada no convívio com as demais idosas. Este espaço que se apresenta (Universidade Sem Limites) possibilita a interação e trocas de experiências e a valorização da família.

\subsection{Contribuições nos Relacionamentos com Amigos/Sociedade}

A criação de laços afetivos na convivência com as pessoas é um acontecimento que dá sentido à vida e se constitui em uma experiência valorosa. Construir novas relações e manter os relacionamentos são valores positivos no envelhecer. Esses fatos são verbalizados nos seguintes discursos:

A gente fica mais animada, conversa com os amigos, brinca, é ótimo [. . . ] fiz muitas amizades e a gente se diverte com todas [. . .] tenho a turma do chimarrão, a turma que a gente vai jantar uma vez por mês [...]. (P6).

[. . .] a gente sempre conversa muito com as amigas, nós temos um grupo especial, fizemos sempre o chimarrão em um lugar, o chá em outra casa, sempre estamos juntas [...]. Nós nos apelidamos de "A MÁFIA" [. . .]. A gente se sente bem mesmo juntas; porque falamos:"Vamos comer pizza hoje? "Vamos?" e "A MÁFIA" se reúne e vai [... .]. (P7).

[ . . ] antes eu não saía, não tinha um grupo de amigas, com quem conversar, eu ficava só na frente da televisão e aquilo não traz nada [. . .] agora tem "A MÁFIA", têm todos os meses janta, agente ri, brinca, enfim é feliz [...]. (P8). 
A gente faz roda de chimarrão com as amigas, conversa, conta piada, dá risada, sai para passear, estou mais solta, dona de minha própria vida, é maravilhoso! (P10).

Fica evidenciado, segundo os recortes das falas acima, o significado da reintegração social, dos novos contatos, novas amizades, resgate da autonomia, independência e valorização pessoal. Fatores capazes de modificar positivamente a visão sobre o envelhecimento, tanto na óptica das idosas quanto na da sociedade. É possível observar a identificação que o grupo estabelece e a manifestação do sentimento de pertença, o que permite o florescimento da criatividade, do companheirismo e da força que as une, passos em direção a um objetivo comum: um envelhecimento saudável.

Para Souza (2001), a autonomia dos alunos estimula não somente a criatividade, as relações interpessoais, a troca de experiências em todos os sentidos, mas também lhes concede voz e vez para se comportarem como sujeitos realmente ativos de um grupo de envelhecimento saudável em todos os aspectos. A auto-gestão possibilita, acima de tudo, que o aluno participante seja também professor e pesquisador de sua própria velhice.

\subsection{Contribuições no Exercício de sua Cidadania}

Esta temática apresenta o exercício da cidadania com um aspecto capaz de promoção da capacidade de exigência dos direitos e da autonomia de pensamento. Como membros úteis da sociedade, os idosos atuam com base em princípios sociais e humanísticos.

[. . .] ajudou muito, porque toda vez que eu era solicitada para fazer alguma coisa, me sentia muito tímida, e hoje não! Eu participei da reforma da igreja [. . .] hoje eu tenho vez e voz e antes eu não tinha essa coragem, os que convivem comigo apreciam minha opinião, isto é muito importante. (P2).

[...] eu sempre participei de muitas coisas, duas vezes fui presidente do Lions, [ . . ] sempre tive uma vida social ativa e procuro manter agora, não é porque tenho mais idade que estou impossibilitada de participar, muito pelo contrário, hoje, tenho experiência, que antes não tinha. (P3). 
Estou mais comunicativa com o pessoal do prédio, com os amigos, aprendi lidar melhor com as pessoas, tomar decisões sem muito medo, antes minha única preocupação eram os filhos e os netos agora me envolvo na comunidade, participo, dou opinião [. . .] vou ao banco, faço compras, tomo minhas próprias decisões, não dependo mais dos filhos. (P4).

Depois da entrada na URI, eu comecei a participar da pastoral da saúde, uma vez por mês agente visita os doentes que não podem participar da comunidade [. . . ] Participo também no Hospital de Caridade, a cada 15 dias eu tiro uma tarde para estar com os doentes. (P5).

Constatam-se, no desvelar dos fragmentos das falas, a influência do meio sob as atitudes das idosas e a visível mudança positiva que o Projeto Universidade Sem Limites desencadeou em suas vidas. Muitas dessas idosas descobriram seus potenciais e capacidades que antes estavam no anonimato. Foram conhecendo um novo grupo de convívio social e desenvolvendo habilidades antes desconhecidas. A influência do grupo foi positiva e benéfica para todas as idosas entrevistadas, que declararam as mais variadas situações em que superaram dificuldades antes existentes.

Objetivos em comum uniram essas idosas em um grupo diferenciado de terceira idade, elas aguçaram o lado intelectual, aprendendo, por exemplo, a tomar decisões, a organizar eventos e a gerenciar essa nova etapa de suas vidas, que talvez fosse vista preconceituosamente como o fim; hoje elas vêem como um novo começo. Todaro (2005) focaliza que a educação permanente representa uma construção contínua dos conhecimentos e aptidões do ser humano, assim como de sua capacidade de agir, permitindo-lhe tomar suas próprias decisões e ter consciência de si próprio e do mundo que o rodeia, sendo um modo de exercer sua cidadania conscientemente.

Para Cachioni (1998) os programas oferecidos pelas universidades abertas para a terceira idade propiciam oportunidades para a participação em atividades intelectuais, físicas, sociais e de lazer. A autora pressupõe que a atividade promove a saúde, o bem-estar psicológico e social, e a cidadania desta clientela chamada terceira idade. 


\section{Considerações Finais}

O estudo mostrou que a universidade aberta para a terceira idade (Universidade Sem Limites) é um modelo inovador de atenção, ampliado e integralmente voltado para os desafios dessa população, proporcionando mudanças substantivas em seus participantes, uma vez que oferece oficinas educacionais (aulas de línguas, italiano e espanhol, e informática); atividades culturais e artísticas; palestras em diferentes áreas do conhecimento como saúde, cidadania, bem-estar social; exercícios de alongamento realizados duas vezes por semana. Ainda oportuniza às suas participantes momentos de integração e ampliação do círculo de amizades.

A inserção dos idosos nos programas de educação permanente permite o processo de ressignificação das experiências de vida anteriores à velhice e, principalmente, das vivências experimentadas e sentidas durante o envelhecimento que ora floresce. Assim, o entendimento do envelhecer assume um significado diferente, onde as participantes do estudo fazem referência a um rejuvenescimento, que pode ser muito bem compreendido como uma renovação do próprio projeto de vida, dos ideais, das perspectivas e expectativas. É, na verdade, um rever de sonhos e objetivos, o assumir um compromisso consigo mesmo e com a vida em busca da felicidade. Esses novos horizontes que se abrem promovem condições para que o idoso experimente maior liberdade interior e exterior e sinta e expresse a sua personalidade de forma mais autônoma e autêntica, tornando-se um evento encorajador da solidificação do pleno exercício da cidadania.

Vale destacar a importância de se desenvolverem modelos de atenção à saúde do idoso que superem as práticas tradicionais, pois o atendimento que lhes é oferecido habitualmente restringe-se, na melhor das hipóteses, ao tratamento clínico de doenças específicas.

É essencial, portanto, que esta experiência se multiplique de modo a estender os benefícios de tais práticas a um maior número possível de cidadãos da terceira idade. Esse processo gerador de conhecimento que respeita as individualidades deve ser experimentado por muitos idosos, pois é mediante as oportunidades que o ser humano se desenvolve, compartilha experiências e se percebe como um indivíduo essencial e capaz de transformações e contribuições à sociedade. 


\title{
CONTRIBUTIONS OF UNIVERSIDADE SEM LIMITES - A PROGRAM OF UNIVERSIDADE REGIONAL INTEGRADA - CAMPUS DE ERECHIM/RS - TO HEALTHY AGING
}

\begin{abstract}
This is a qualitative study of exploratory and descriptive approach, with the participation of 10 elderly people from "Universidade sem limites", a program of Universidade Regional Integrada - Campus de Erechim/RS. The objective of this study was to identify the contributions to the elderly's live, with them taking part of this program. The data were collected from a semi-structured interview with a question: What contributions has your participation in the program "Universidade Sem Limites" brought to your life? Data analysis allowed the division of the information into four main areas: Contributions to personal life: better self-esteem, auto-image and cognition. Contributions to life in family: better intergenerational relations. Contributions to social life: stimulus to social life, autonomy, independence and responsability towards their own life and the others. Contributions to their own citizenship: capacity to demand for their rights, and autonomy of thought, being utile members of society, acting based upon social and humanistic principles. The participation of the elderly in this program contributes singularly to many aspects of their lives. Therefore, this program is a possibility that the elderly have to become age healthily, interacting with other people of their age and developing physical, cognitive, social, emotional, and spiritual aspects, being the their own agents of the educative process, which contributes to having better health and quality of life and emphasizes their socio-emotional life experiences. Keywords: Aging. Quality of life. University for the elderly. Education.
\end{abstract}

\section{REFERÊNCIAS}

ARANDA, Julio Inga; HORNA, Arístides Vara. Calidad y Satisfacción de Vida de Adultos Mayores en Lima-Perú: estudo piloto y análisis psicométrica. Asociación por la defensa de las Minorías (ADM). Disponível em: <http://www.geocities. com/Heartland/Cabin/5900/adulto.htm>. Acesso em: 25 nov. 2007. 
BERLIZI, Evelise Moraes; ROSA, Patrícia Viana da. Estilo de Vida Ativo e Envelhecimento. In: TERRA, Newton Luiz; DORNELLES, Beatriz (Org.). Envelhecimento Bem-sucedido. Porto Alegre: EDIPUCRS, 2002. P. 91-96

BOUTIQUE, Nanci Catharina; SANTOS, Rosa de Lourdes Azevedo dos. Aspectos Socioeconômicos do Envelhecimento. In: NETTO, Matheus Papaléo. Gerontologia. São Paulo: Atheneu, 2005. P. 82-91

CACHIONI, Meire. Envelhecimento Bem-Sucedido e Participação numa Universidade para a Terceira Idade: a experiência dos alunos da Universidade São Francisco. 1998. 104 f. Dissertação. (Mestrado em Educação)-Faculdade de Educação, Universidade Estadual de Campinas, Campinas, 1998.

CACHIONI, Meire. NERI, Anita Liberalesso. Educação e Velhice Bem-Sucedida no Contexto das Universidades da Terceira Idade. In: YASSUDA, Mônica Sanches; NERI, Anita Liberalesso; CACHIONI, Meire (Org.). Velhice Bem-Sucedida: aspectos afetivos e cognitivos. 2. ed. Campinas: Papirus, 2004. P. 29-49.

CELICH, Kátia Lilian Sedrez. Dimensões do Processo de Cuidar: a visão das enfermeiras. Rio de Janeiro: EPUB, 2004.

GOLDMAN, Sara Nigri. As Dimensões Sociopolíticas do Envelhecimento. In: PY, Ligia et al. (Org.). Tempo de Envelhecer. 2. ed. Holambra: Setembro, 2006. P. 57-76.

INSTITUTO BRASILEIRO DE GEOGRAFIA E ESTATÍSTICA. Censo Demográfico, 2000. Disponível em: <http://www.ibge.net/home/estatística/população/ censo2000>. Acesso em: 25 de maio 2007.

IRIGARAY, Tatiana Quarti. Dimensões de Personalidade, Qualidade de Vida e Depressão em Idosas da Universidade para Terceira Idade. 2006. 150 f. Dissertação. (Mestrado em Gerontologia Biomédica) - Programa de Pós-Graduação em Gerontologia Biomédica. Pontifícia Universidade Católica do Rio Grande do Sul, Porto Alegre, 2006.

JECKEL NETO, Emilio Antonio. Tornar-se Velho ou Ganhar idade: o envelhecimento biológico revisitado. In: NERI, Anita Liberalesso (Org.). Desenvolvimento 
e Envelhecimento: perspectivas biológicas, psicológicas e sociológicas. Campinas: Papirus, 2001. P. 39-52.

MARIN, Maria José Sanches. et al. Estimulando o Autocuidado em Grupo da Terceira Idade Através de Jogo Educativo Tipo Bingo. Revista Enfermagem Atual. Ano 3, n. 15, p.15-18. maio/jun. 2003.

MINAYO, Maria Cecília de Souza. O Desafio do Conhecimento: pesquisa qualitativa em saúde. 7. ed. São Paulo: Hucitec, 2000.

MORAES, João Feliz Duarte de. Fatores Determinantes do Envelhecimento BemSucedido do Idoso Socialmente Ativo da Região Metropolitana de Porto Alegre. 2004. 137f. Tese. (Doutorado em Medicina) - Instituto de Geriatria e Gerontologia, Pontifícia Universidade Católica do Rio Grande do Sul, Porto Alegre, 2004.

MORAGAS, Ricardo Moragas. Gerontologia Social: envelhecimento e qualidade de vida. São Paulo: Paulinas, 1997.

NERI, Anita Liberalesso. Atitudes em Relação à Velhice In: NERI Anita Liberalesso (Org.). Palavras Chaves em Gerontologia. 2. ed. Campinas: Alínea, 2005. P. 13-15.

NETTO, Matheus Papaléo; PONTE, J. R. Envelhecimento: desafio na transição do século. In: NETTO, Matheus Papaléo. Gerontologia. São Paulo: Atheneu, 2005. P. $3-12$

PALMA, Lucia Terezinha Saccomori. Educação Permanente e Qualidade de Vida: indicativos para uma velhice bem-sucedida. Passo Fundo: UPF, 2000.

PARENTE, Maria Alice de Mattos Pimenta. Envelhecimento: um processo adaptativo multifatorial. In: PARENTE, Maria Alice de Mattos Pimenta. (Org.) Cognição e Envelhecimento. Porto Alegre: Artmed, 2006. P. 17-18.

PORTELLA, Marilene Rodrigues. Pesquisa em cuidado no processo de envelhecimento. Texto Contexto Enferm., Florianópolis v. 10, n. 2. maio/ago. 2001, P.196-202. 
PORTELLA, Marilene Rodrigues. Grupos de Terceira Idade: a construção da utopia do envelhecer saudável. Passo Fundo: UPF, 2004.

SOUZA, Luciana Karine de. Uma Nova Chance: o idoso na universidade. In: CASTRO, Odair Perugini de. et al. Envelhecer: um encontro inesperado? Realidades e perspectivas na trajetória do envelhecer. Sapucaia do Sul: Notadez, 2001. P. 93-120. .

TODARO, Mônica de Ávila. Educação Continuada, Educação Permanente. In: NERI, Anita Liberalesso. (Org.). Palavras-Chave em Gerontologia. 2. ed. Campinas: Alínea, 2005. P. 63-67

UNIVERSIDADE REGIONAL INTEGRADA DO ALTO URUGUAI E DAS MISSÕES. Projeto Social: integração da universidade com a terceira idade. Erechim: CETEX, 2006. Projeto Universidade Sem Limites do Departamento de Ciências Humanas.

VASCONCELOS, Eymard Mourão. Educação Popular e a Atenção à Saúde da Família. 2. ed. São Paulo: Hucitec, 2001.

VERAS, Renato Peixoto.; CALDAS, Célia Pereira. Promovendo a Saúde e a Cidadania do Idoso: o movimento das universidades da terceira idade. Ciências da Saúde Coletiva, Rio de Janeiro v. 9, n. 2. abr./jun. 2004. P.423-432.

Recebido em: 17/07/2007

$1^{a}$ revisão: $18 / 09 / 2007$

Aceite final: 06/03/2008 